\title{
O DE REPUBLICA E O "PRINCEPS" CICERONIANO (Notas de Leitura)
}

\section{Aída Costa}

Em 57 voltava Cícero da Grécia, de um exílio de dezoito meses, a que fora condenado no ano anterior, por força de intrigas políticas, naqueles atribulados dias da República.

Breve se the esvaecem as esperanças de tornar à vida pública, restando-lhe apenas a atividade intelectual. Aproveita-se, então, deste primeiro recesso (1), para compor sua grande obra retórica, o De oratore libri III. em 55, e seu grande trabalho político, o De Repríblica, iniciado em 54 e publicado em 51, obra que é complementada pelo De legibus, começado em 52. Nessas obras, faz Cícero, respectivamente, a descrição do governo perfeito e o estudo da legislação do Estado, cuja constituição propõe.

Fruto de longa reflexão e de vivida. de sofrida, experiência política, é o De Republica um diálogo à moda platônica, mantido durante três dias, no ano de 129 a. C., por personagens ilustres de gerações anteriores, como Cipião Emiliano, Lélio, Tuberão, Múcio Cévola.

Pretendeu Cícero, sem dúvida, expor e justificar suas idéias políticas, as quais não são, essencialmente, as mesmas da Republica de Platão (2), obra que lhe serviu, entretanto, inquestionavelmente, de modelo, ao menos do ponto de vista da forma.

A doutrina política de Cícero distingue-se, em seus fundamentos, da de Platão, pelo fato de ser uma doutrina construída sobre uma realidade histórica, a experiência romana, enquanto a "politéia" platoniana é concepção filosófica, estado ideal, em que o filósofo teria pensado realizar seu ideal supremo de vida política, de sociedade humana regularmente organizada, que tem na justiça sua pedra basilar.

(1) - 57-51: proconsulado ra Cilícia.

(2) - A palavra latina respublica corresponderia à grega joגiteíu. 
Defrontam-se nas obras de Cícero e de Platão, em seu caráter antagônco intrínseco, as duas mentalidades, a romana e a grega, pelas dimensões em que se define o reali mo pragmatista do romano e o idealismo teórico do grego. Do esquema de Cícero está excluído o que há de utópico em Platão.

Compõe-se o De Republica de seis livros. Cipião Emiliano (I, 26) começa por distinguir, nessa obra, três formas elementares de governo: monarquia, aristocracia e democracia .

Perfilhando as idéias de Políbio, historiador grego, um dos inspiradores do humanismo do Círculo dos Cipiões, condena Cícero essas formas de governo, que se abastardem, incapazes de manter-se por muito tempo. A monarquia degenera na tirania, a aristocracia, na oligarquia. O oligarquia conduz à democracia através da rebelião popular e a democracia degenera em oclocracia, a "fera de muitas cabeças"

Cícero repele a supremacia do número, que desconhece o mérito: "eaque quae appellatur aequabilitas, iniquissima est" (I, 34), "csta pretendida igualdade é totalmente contrária à equidade" A fórmula ciceroniana, inspirada em Aristóteles, que afirma que "a igualdade parece ser justa, e o é com efeito, mas entre iguais, não entre todos", é também a idéia que se encontra no Capitulo $\mathrm{V}$ das Leis de Platão.

O excesso de liberdade degenera em licença: "Cum enim, inquit, inexplebiles populi fauces exaruerunt libertatis siti, malisque usus ille ministris non modice temperatam, sed nimis meracam libertatem sitiens hauserit" (I, 43). Quando a sede popular é impossível de saciar, maus servidores bebem a liberdade como beberam vinho. com as goelas insaciáveis, sem lhes abrandar o ardor"

A aristocracia é a pior das formas de governo: "nec ulla deformior species est ciuitatis, quam illa, in qua opulentissimi optimi putantur" (I, 34), "nenhuma cidade está mais longe da perfeição que aquela na qual se crê que os mais ricos são os melhores"

Para Cícero, a menos má das três formas de governo é a monarquia, a respeito da qual diz, pela boca de Cipião, respondendo a Lélio: "Tens razão de perguntar qual dessas formas eu prefiro, porque não aprovo totalmente nenhuma. Ponho acima de cada uma a combinação das três. Se, entretanto, fosse preciso escolher uma delas, optaria pela realeza", (I, 35). 
Não se pode deixar de pensar aqui em sugestões de Políbio a Platão. Dizia Políbio ser próprio de um rei fazer a todos o bem, inspirar amor, o que significa valorização do regime monárquico, contrastando com os demais regimes de governo. Platão, por sua vez, declara, sem nenhum subterfúgio, que a monarquia é o melhor dos

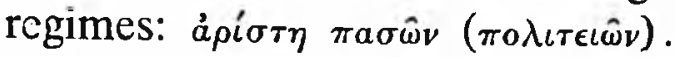

Haver em Cícero tais sugestões de Políbio e Platão a respeito da superioridade da monarquia não significa aceitá-la o escritor latino como forma ideal de governo. Ao contrário, faz-lhe Cícero a severa restrição de ser ela passível de degenerar em tirania. Seu ceticismo a propósito da monarquia fica muito claro quando afirma que pouco importa seja ou não o déspota clemente, seja ele indulgente e humano, quando se é escravo $(I, 33)$

Para Cícero o estado ideal é a "res populi", isto é, o estado em que se respeitem os direitos individuais e a comunidade de interesses dus cidadãos; "Est igitur, inquit Africanus, (replicando a Lélio) respublica, populi: populus autem non omnis hominum coetus quoque modo congregatus, sed coetus multitudinis iuris sensu et utilitatis communione sociatus (I, 24). ("A coisa púb.ica, pois, diz Cipião, é a coisa do povo; e por povo é preciso entender, não toda a assembléia de homens reunidos em rebanho, de uma maneira qualquer, mas um grupo numeroso de homens associados uns aos outros por sua adesão a uma mesma lei e por uma certa comunidade de interesses").

Não é outro o sentido das palavras de Cipião a Lélio: "Quid es.t enim ciuitas nisi iuris societas?" "Que é, pois, uma cidade se não uma sociedade de cidadãos que têm o mesmo direito?"

Recusando cada uma das três formas de governo, das quais aponta os inconvenientes que lhes são próprios, o mais importante dos quais é um inevitável abastardamento, Cícero define-se por um regime ideal. O regime ideal que propõe não apresenta os riscos da aristocracia, da democracia, da monarquia, mas reúne seus postulados fundamentais.

Qual a forma ideai? -- $\mathrm{O}$ da constituição romana (3), que resume e modera os três poderes: a realeza, nos cônsules; a aristocracia, no senado; a democracia, na parte que o povo toma no governo, por meio de suas instituições e de seus direitos.

(3) - A antiga política, sábia e poderosa, do estado romano, encarecida por Políbio. 
Desse modo, os três grandes princípios da sabedoria política e da constituição romana, isto é, a potestas, a auctoritas, a libertas, seriam os elementos fundamentais de um governo perfeito.

E' a síntese da antiga política romana: "Sic enim decerno, sic sentio, sic affirmo, nullam omnium rerumpublicarum, aut constitutione ,aut descriptione, aut disciplina conferendam esse cum ea, quam patres nostri nobis acceptam iam inde a maioribus reliquerunt" (I, 46), "Eu vejo, eu creio, eu afirmo, não há regime que, por sua estrutura, o modo pelo qual são distribuídos os direitos e os deveres, sua legislação, possa ser comparado com o que os nossos pais receberam de seus antepassados para no-lo transmitirem"

E' aquele sentido político inato no romano, aquela sua vocação de liderança' em contraste com a vocação da ciência e da especulação desinteressada dos gregos, que Vergílio proclama nos famosos versos do Canto VI da Eneida, quando, após terem desfilado diante dos olhos maravilhados de Enéias as almas troianas que esperavam nos infernos o momento de reincarnar-se nos futuros romanos que fariam a glória de Roma, assim fala o pai Anquises:

Excudent alii sperantia mollius aera

(Credo equidem), uiuos ducent marmore uoltus, orabunt causas melius, caelique meatus, describent radio et surgentia sidera dicent: tu regere imperio populus Romane, memento (hae tibi erunt artes), pacisque imponere morem, parcere subiectis et debellare superbo (VI, 847-856).

No Livro II, Cícero procura demonstrar como se atinge a perfeição através de uma longa experiência e conclui que, sem uma e-trita justiça, nenhum governo é possível: "sine summa iustitia rempublicam geri nullo modo posse" (II, 44) .

No Livro III, ele discute a justiça: Lélio admite que existe uma iustiça e que nela se fundamenta o governo do povo. Filão, ao contrário, crê que as leis sociais nascem da utilidade e da violência, às quais se quer arbitrariamente dar o nome de justiça.

E' uma alusão às doutrinas de Carnêades (4): "Credo quoniam de republica disserebat, ut defensionem laudationemque eius induceret

(4) - Filósofo grcgo que deservolveu as iciéias da "Nova Academia", e combateu rudemente os estóicos 
sine qua putabat regi non posse rem publicam" (III, 6), "tratando da república, ele queria, penso, levar a defesa e o elogio da justiça, necessária, segundo acreditava, à gestão da coisa púbiica"

No Livro IV, do qual pouco resta, trata Cícero da educação moral dos cidadãos e do valor educa.ivo da arte.

Pouco subsiste também do Livro $\mathrm{V}$, iniciado com o famoso verso de Enio: "Moribus antiquis res stat Romana uirisque" "O estado romano ergue-se sobre os antigos costumes e os antigos cidadãos"

Neste livro propõe Cícero problema que fascina o historiador e o moderno crítico de Cícero: Qual seria o perfeito homem de estado, o perfeito governante?

Cícero terá fixado aí o conceito de um "moderator rei publicae" E', pelo menos, o que ele próprio afirma em carta a Ático: "nam sic quinto, ut opinor, in libro loquitur Scipio" "Ut enim gubernatori cursus secundus, medico salus, imperatori uictoria, sic huic moderatori rei publicae beata ciuium uita proposita est, ut opibus firma copiis locuples, gloria ampla, uirtute honesta sit. Huius enim operis maximi inter homines atque optimi illum esse perfectorem uolo" (VIII, 11). Eis como fala Cipião, no Livro V. se não me engano: "Como o piloto se propõe uma travessia feliz, o médico, a saúde, o general, a vitória, assim, o que tem em vista meu dirigente da república é para os cidaaũos uma vida feliz, cheia de recursos, rica de dinheiro, aureolada de glória, bela por sua virtude. Tal é a tarefa, a maior, a melhor que existe no mundo, que eu quero que ele realize"

Além dessas palavras conservadas na carta a Âtico e que se referem expressamente ao governante perfeito, há o passo de Santo Agostinho, "Epit.", 104, 2, 5, que é o seguinte: "Et ubi est, quod et uestrae litterae illum laudant patriae rectorem qui populi utilitate magis consulat quam uoluntati?" "Onde está, pois, aquele que celebram os vossos autores, homem que dirige os negócios da pátria, que prefira considerar o interesse do povo a consultar sua vontade?"

O mesmo Santo Agostinho, em Cidade de Deus (V, 13) reproduz o termo "princeps", de que se servira Cícero, para designar o governante ideal: "Etiam Tullius hunc dissimulare non potuit in eisdem libris quos de republica scripsit, ubi loquitur de instituendo principe ciuitatis quem dicit, "alendum esse gloria et "consequentur commemo- 
rat "maiores suos multa mira atque praeclara gloriae cupiditate fecisse" (De Rep., V, 6), "Cícero, ele próprio, não o pode dissimular, no tratado que escreveu sobre a república, no passo em que diz que se deve instituir um "princeps" da cidade, que é preciso alimentá-lo de glória, e lembra, em consequiência, que os antepassados dos romanos fizeram pelo desejo de glória muitas coisas magníficas e dignas de admiração"

E' assim que aparece nesses fragmentos, o "princeps", que tanto tem dado a pensar a historiadores e críticos do pensamento e da literatura romana. Vamos procurar fixar, a propósito do "princeps", os principais enfoques da historiografia moderna, servindo-nos, dentre outras obras que tratam do assunto, do excelente trabalho de Ettore Lepore, Il princeps ciceroniano.

A partir de Reitzenstein (5), 1917, a pesquisa lingüística e filológica tem aprofundado o estudo dos vários termos-chave do problema contidos no texto ciceroniano.

Os termos "rector" "gubernator", "moderator" (De Rep. II, 29) e mais "tutor" "procurator" e outros, não permitem aceitar tranqüilamente a' opinião de Homo, o qual pretende ver nas idéias de Cícero uma fórmula velada de definições do sistema do Principado, identificando o ideal ciceroniano com o poder monárquico ou comum do "Inus"

Os termos "tutor" e "procurator" designam no De Oratore, obra escrita, como o De Republica, durante o recesso de 57-51, funções de magistrados ordinários ou a atividade dos membros do Senado.

Do mesmo modo, o termo "rector", que já aparece no "De ora-

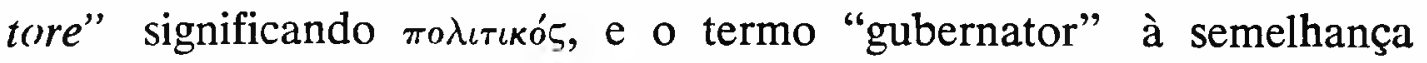
do que ocorre com a palavra "custos", são empregados por Cícero com seu valor corrente, sem nenhum significado especial.

(5) - Die Idee des Prinzipats bei Cicero und Augustus, in "Nachrichten de Göttigen Geschichte Gesellschaft", 1917. 
Outro tanto se pode dizer com relação a "moderator", que, embora anteriormente raro, está implícito no verbo "moderare", no $\mathrm{De}$ oratore, I, 211, passo no qual se fala também de um "rector" (6).

Em alguns passos, aliás, ao lado desses termos, aparece a fórmula mais genérica "hic uir", "ille uir", o que nos poderia levar a

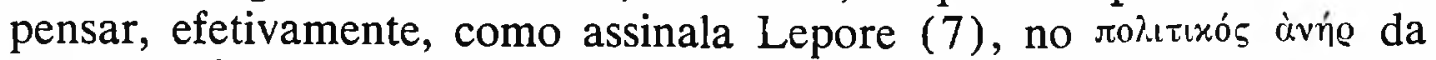
Carta a Ático (I, 18, 6): "Agraria autem promulgata est a Flauio,

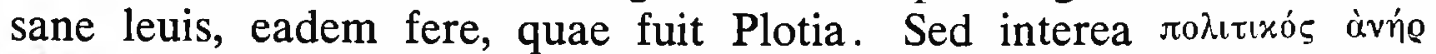
oủd'óvae quisquam inueniri potest", "Por outro lado, Flávio propôs a lei agrária, lei muito pobre, e que lembra, mais ou menos, a de Plócio. Mas o impossível em tudo isso é encontrar-se um verdadeiro político ou sequer sua sombra"

O exame lingüístico conduziria, assim, a uma aproximação do

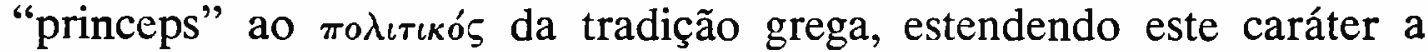
todo aquele que "erit rector et gubernator ciuitatis", excluindo, possivelmente, uma interpretação monárquica de preeminência de um só.

De qualquer maneira, o problema é muito complexo e em sérios embaraços nos encontraríamos se tivéssemos que assumir uma das várias posições adotadas pela historiografia moderna.

A problemática do "principado" ciceroniano impregnou-se de vivo caráter polêmico, nos últimos tempos, principalmente na Alemanha.

Ainda de Ettore Lepore (7), que trata exau tivamente do assunto, servimo-nos para assım sumariar e dar ordem cronológica a esses estudos:

(6) - "Sin autem quaereremus quis esset is, qui ad rem publicam moderandam usum et scientiam et studium suum contulisset, definirem hoc modo: qui rebus utilitas rei publicae pararetur augereturque teneret eisque uteretur hunc rei publicae rectorem et consuli publici auctorem esse habendum, praedicaremque $P$. Lentulum principem illum et Ti. Gracchum patrem et Q. Metellum et $P$. Africanum et Caium Laelium et inumerabiles alios cum ex nostra ciuitate tum ex ceteris". "Se fosse preciso definir o cidadão que consagra à direção da coisa pública sua experiência, suas luzes, sua dedicação, eu me exprimiria assim: aquele que conhecendo os meios de criar, de desenvolver a prosperidade de seu país, emprega com sucesso estes meios, esse deve ser considerado como verdadeiro chefe de estado, como a alma dos conselhos da cidade: eu proclamaria P. Lêntulo o principal do senado, Tibério Graco, o pai, Quinto Metelo, o segundo Africano, Lélio e outros inumeráveis, tanto entre nós, como entre outras nações".

(7) - LEPORE, Ettore - Il princeps ciceroniano e gli ideali politici della tarda Republica. 1954, p. 71. 
Drumann, em Geschichte Roms in seinem Uebergange von der Republicanischen zur Monarchischen Verfassung, em 1884, e também Mommsen haviam lançado Cícero ao descrédito. Investiram, ao mesmo tempo, contra o homem de estado e contra sua obra literária.

Após a primeira guerra mundial e, ainda mais, após a segunda guerra, procurando interpretar e definir o ideal do "princeps" delineado por Cícero no De Republica, e em outras obras suas, e confrontá-lo com a política de Cícero, na crise que levou Roma ao principado de Augusto, um grande número de obras surge na Europa e, sobretudo, na Alemanha.

Inicia - como lembramos atrás - esses estudos Reitzenstein (Die Idee des Prinzipats bei Cicero und Augustus), em 1917, chefianJo a corrente que vê no De Republica a obra doutrinária que prepa. ra o caminho para o "princeps" produto da tradição romana e da filosofia grega.

Para Reitzenstein, o "princeps" ciceroniano deveria exercer o poderio universal, justificando-se, assim, o poder supremo de um só do principado de Augusto.

Essa compreensão do pensamento ciceroniano, entranhado de cultura helenística, não se libertou, porém, dos resíduos mommsenianos de um falso realismo, assim como de uma abstrata caracterização cultural do escritor, que prejudicam a total compreensão de sua individualidade.

A Reitzenstein, segue-se Eduard Meyer, o qual, em sua obra Caesars Monarchie und das Principat des Pompeius (Stuttgart-Berlim), publicada em 1918, faz a gênese da história imperial, considerando o De Republica como obra justificativa da posição de Pompeu cm 52 .

Secundando a tese de Eduard Meyer, contemporaneamente, E. Ciaceri, em seu Il tratato di Cicerone "De Republica" acentua a simpatia de Cícero pela concentração de poderes nas mãos de um só, tese pelo autor desposada também no livro Cicerone e $i$ suoi tempi.

E' de Heinze, Ciceros Staat als politische Tendenzschrift, in Hermes, 1924, um dos trabalhos mais sutis que se escreveram até hoje, sobre a matéria, tomando a crítica histórica uma nova direção. Heinze nega tendência monárquica ao De Republica. Cícero, com seu "princeps" não teria querido designar um só homem. Aduz Heinze que, quando ilustra seu ideal acerca da atividade do homem de estado, 
Cícero se comporta da mesma maneira que quando fala do "orator"

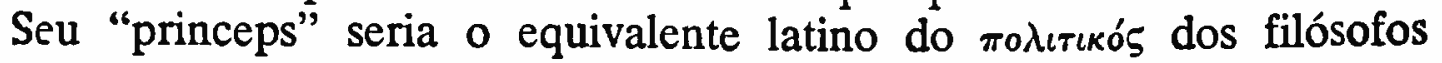
gregos.

Tratar-se-ia, pois, segundo Heinze, não de uma justificação do poder pessoal de um só, mas do ideal de uma classe política ,que, com a restauração da antiga república, viria a ser constituída pela velha aristocracia romana, moralmente regenerada, isto é, pelos "principes"

Para Francesco Arnaldi, Heinze, com efeito, defende a tese de que Cícero no De Republica jamais usou a palavra "princeps" para referir a pessoa de posição excepcional no Estado (8).

O defeito do método de Heinze, parece, é o mesmo que o dos seus predecessores: Heinze ficaria muito ligado ainda ao aspecto formal dos fenômenos e sua indagação semântica e léxica pecaria por falta de profundidade na penetração do instrumento filológico.

Após Reitzenstein, Eduard Meyer e Heinze, a historiografia mais recente derivou para os rumos que assim se podem inventariar:

Um grupo reduzido que aceita, sem modificações substanciais, a teoria de Heinze, que nega tendência monárquica ao De Republica, tendo como certo que o "princeps" único, de Cícero equivaleria ao

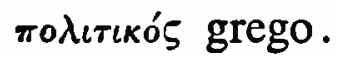

Pertence a esse grupo, por exemplo, Kroll, em Die Kultur der ciceronischen Zeit, Leipzig, 1933, para o qual, o "princeps" ciceroniano é um ideal de classe dirigente conservadora, sem nenhuma tendência monárquica e sem nenhuma simpatia pelo poder predominante de um só.

Outro grupo, crendo na interpretação de Reitzenstein, que vê no "princeps" ciceroniano um chefe de estado com prerrogativas monárquicas e poderes absolutos, admite uma relação entre esse pensamento político e as realizações de Augusto.

Duas correntes contribuíram para consolidar a teoria do "princeps" monárquico: a corrente que defendeu a importância do neopitagorismo na formação da tradição monárquica helenística (9) e romana, representada por Goodnough, em The political Philosophy of hellenistica Kingship, "Yale Classical Studies", I, 1928, e a corrente

(8) - Cicerone, Gius. Laterza \& Fili, 1948, p. 174.

(9) - Cf. CIACERE, E. Cicerone e i suoi tempi. 1.a ed., Milano, Napoli, 1926-30, 2.a ed. 1939-41. 
que se volta para a pesquisa sobre a tradição romana dos Cipiões, na qual vê prenúncio de governo de um só.

Esta é a tese, por exemplo, de Kaerst, em Scipio Aemilianus, die Stoa und der Prinzipat, in "Neue jahrtausenden politisch Tradition", dc 1930 .

O terceiro grupo, o mais numeroso, reúne, parece, o maior número das opiniões na atualidade: é o que distingue as idéias do "princeps" ciceroniano dos da monarquia constitucional, que Meyer identificava, vendo no "princeps" uma determinada pessoa, quer fosse o próprio Cícero quer fosse Pompeu.

Adotam essa interpretação, entre outros, Francesco Arnaldi (10) e Ciaceri (11).

Assim, chega a historiografia com tantos trabalhos e tão sérias pesquisas, a um resultado positivo, que é o da separação definitiva da teoria ciceroniana da realização de Augusto, como já se observou.

Não deixa dúvidas sobre essa mais recente posição Grénade, quando em Mélange d'architecture et d'histoire, LVII, 1940, p. 63, assinala que é "imensa a distância entre a teoria ciceroniana, dita do principado, e a realização do principado de Augusto, isto é, a distância que separa a direção moral para uma política desinteressada de um estado equilibrado e uma monarquia de fato dissimulada sob as aparências do equilíbrio mantido dos poderes"

Estabelece-se, pois, um duplo plano para a obra de Cícero, o da especulação abstrata e o da realização concreta, que corresponderia a dupla personalidade do autor.

Em contrapartida, Lepore (12) retoma a discussão da matéria, apelando para argumentos lingüístico-filosóficos, parecendo convencido de que o ideal do "princeps" ciceraniano é um ideal que procura seu fundamento nas contingências e nas relacões concretas da força e dos interesses em jogo, situações precisas, tendo sempre como exigência a de adequar-se a uma realidade, tornando-a adequada a ele.

De qualquer forma, é a figura do governante do De Republica, figura idealizada e quase divinizada: Cícero chama ao homem de es-

(10) - Op. cit.

(11) - Op. cit., I, 29.

(12) - Op. cit., p. 305 . 
tado de "quase divino": "atque in sua potestate retinentem magni cuiusdam ciuis et diuini paene est uiri" (13).

Chama atenção Bignone (14) para o ponto de transição da parte teórica do De Republica para a parte poética e mística do Livro V, o famoso "Somnium Scipionis", no qual Cícero se propõe emular o mito de Er da Republica de Platão.

A Republica de Platão termina com o mito de Er, ressuscitado. Este mito escatológico revela o destino e o julgamento da alma na vida ultraterrena.

O Somnuim Scipionis tem um caráter mais romano, é mais história que lenda; é história romana, de fundo e poesia romana"

Inspirou-se Cícero, com certeza, em uma das obras, para nós perdidas ,obras platonizantes de Aristóteles, o Eudemo. Cícero a conhecia, como vemos em De diuinatione, I, 25, 42. Tinha o Eudemo como fundamento da revelação mística um sonho profético conhecido como realidade histórica.

Por outro lado, não pode deixar-se de relacionar a revelação post mortem na versão onírica de Cícero com a revelação da vékvıa homérica e a romana revelação de Enéias no Canto VI do poema vergiliano.

O contato ultraterreno do "Sonho de Cipião", não é uma descida aos Infernos, como a de Orfeu e a de Enéias, mas uma ascensão às esferas celestes, as quais são a verdadeira pátria da alma .

Vindo da África, perto de Massinissa, Cipião teria tido uma visão em que o grande Cipião Africano the teria aparecido e, do lugar celeste, iluminado por fúlgida luz sideral, the teria feito ver Cartago e lhe teria predito que, dentro de dois anos, seria seu conquistador.

A Lélio e aos outros que o ouvem e vêem revela Cipião que "existe no céu um lugar reservado a todos os que trabalharam pela salvação da pátria, que a ajudaram e engrandeceram, um lugar de beatitude e de vida eterna. Nada existe, efetivamente, diz ele, que o primeiro dos deuses, o que governa o mundo, prefira a essas socie-

(13)-De Republica, 1, 29

(14) - BIGNONE, Ettore - Storia della Letteratura Latina. G. G. Sansoni Editori, v. III, p. 627 
dades humanas aglutinadas pelo direito, que se chamam cidades. Seus dirigentes e seus salvadores, de lá tendo vindo, para lá retornam"

Assim, o "Sonho de Cipião" poderia esclarecer o pensamento de Cícero em relação àquele "princeps", àquele que se consagra ao serviço da pátria, o homem excepcional, de origem celeste, a quem o devotamento à causa pública é passaporte para as esferas celestes, para a eternidade gloriosa 